\title{
Article \\ Optimization Technique for High-Gain CMOS Power Amplifier for 5G Applications
}

\author{
Hayeon Jeong ${ }^{1}$, Huidong Lee ${ }^{2}$, Bonghyuk Park ${ }^{2}$, Seunghyun Jang ${ }^{2}$, Sunwoo Kong ${ }^{2}$ and Changkun Park ${ }^{1, * \text { (D) }}$ \\ 1 School of Electronic Engineering, College of Information Technology, Soongsil University, Seoul 06978, Korea; \\ jhayeon85@soongsil.ac.kr \\ 2 Electronics and Telecommunications Research Institute (ETRI), Daejeon 34129, Korea; leehd@etri.re.kr (H.L.); \\ bhpark@etri.re.kr (B.P.); damduk@etri.re.kr (S.J.); swkong@etri.re.kr (S.K.) \\ * Correspondence: pck77@ssu.ac.kr; Tel.: +82-2-828-7166
}

check for updates

Citation: Jeong, H.; Lee, H.; Park, B.; Jang, S.; Kong, S.; Park, C. Optimization Technique for High-Gain CMOS Power Amplifier for 5G Applications. Appl. Sci. 2021, 11, 11691. https://doi.org/10.3390/ app112411691

Academic Editor: Filippo Giannazzo

Received: 28 October 2021

Accepted: 6 December 2021

Published: 9 December 2021

Publisher's Note: MDPI stays neutral with regard to jurisdictional claims in published maps and institutional affiliations.

Copyright: (c) 2021 by the authors. Licensee MDPI, Basel, Switzerland. This article is an open access article distributed under the terms and conditions of the Creative Commons Attribution (CC BY) license (https:// creativecommons.org/licenses/by/ $4.0 /)$.

\begin{abstract}
In this study, a differential power amplifier (PA) with a high gain of over $30 \mathrm{~dB}$ by configuring a three-stage common source unit amplifier was designed. To ensure the stability of the high-gain differential PA, the analysis to apply the capacitive neutralization method to the differential common source PA was conducted. From the analysis, the required neutralized capacitance was quantitatively calculated from the estimated parasitic components of a power cell used in the PA. To verify the feasibility of the proposed optimization technique, a Ka-band PA was designed with a $65 \mathrm{~nm}$ RFCMOS process. The measurement results showed a gain of $30.7 \mathrm{~dB}$. The saturated output power was measured as $16.1 \mathrm{dBm}$, maximum power-added efficiency (PAE) was $29.7 \%$, and P1dB was $13.1 \mathrm{dBm}$.
\end{abstract}

Keywords: 5G mobile communication; capacitive neutralization; CMOS; high gain; power amplifiers

\section{Introduction}

Recently, with the adoption of fifth-generation (5G) communication standards, active research has been conducted on millimeter-wave (mm-Wave) power amplifiers (PAs); particularly, the demand for monolithic microwave integrated circuit (MMIC) operating at Ka-band frequency to satisfy the $5 \mathrm{G}$ standards is increasing [1,2].

More recently, studies have been underway to configure single-chip transceivers by utilizing high-integrity characteristics of CMOS [3-5]. However, it may not communicate smoothly if the transceiver path lacks gain, which is calculated to determine the appropriate margin when performing link budget analysis. Therefore, to compensate for the lack of gain, a gain amplifier would be required based on the IC specifications, resulting in a larger IC size and complexities. The link-budget calculations in our study show that if a single PA secures a minimum gain of $27 \mathrm{~dB}$, the transceiver IC does not require additional amplifiers, and can be designed to be more marginal.

In this work, a PA capable of obtaining high gain was designed, and the problem of stability that may occur due to the high gain was solved using a neutralization capacitor. To this end, for the first time, we extracted the optimal value of the neutralization capacitor using a differential structure.

\section{Design and Optimization of the Power Amplifier}

Herein, we present the optimization technique and the design process of a high-gain differential PA with the capacitive neutralization method in detail. In this study, a $65 \mathrm{~nm}$ RFCMOS is selected to design a differential three-stage common-source PA with high gain. The target frequency bandwidth is between $26.5-29.5 \mathrm{GHz}$. with a supply voltage of $1 \mathrm{~V}$. Further, a neutralized capacitor $C_{\text {neu }}$ is used to improve the stability of the high-gain PA, and the capacitance required depends on the transistor size [6-8]. 
The design process described below is summarized as follows. First, the size of the transistor to be used in the PA was determined through load-pull simulation. Parasitic components were extracted based on the determined transistor. After that, the optimum value of $C_{n e u}$ was derived using the proposed equivalent circuit of the power cell of the differential structure including $C_{n e u}$, and the equations derived from the equivalent circuit. In this case, the power gain and k-factor of the PA were considered. Finally, the value of $C_{n e u}$ was corrected based on the EM simulation result considering the layout effect.

\subsection{Size Determination of the Unit Amplifier Transistor}

The RFCMOS transistors used in this study had a gate length of $65 \mathrm{~nm}$ with a maximum of 32 fingers. The gate lengths of the transistors used in this study are all $65 \mathrm{~nm}$. The transistor size was adjusted by changing the width of the unit finger, total number of fingers, and multiplier. Figure 1 shows the maximum available gain (MAG) according to the transistor size at $350 \mathrm{mV}$ gate bias voltage. As the gate width changes from $80 \mu \mathrm{m}$ to $256 \mu \mathrm{m}$, the single-stage MAG ranges between 8 and $11.5 \mathrm{~dB}$ at $28.5 \mathrm{GHz}$.

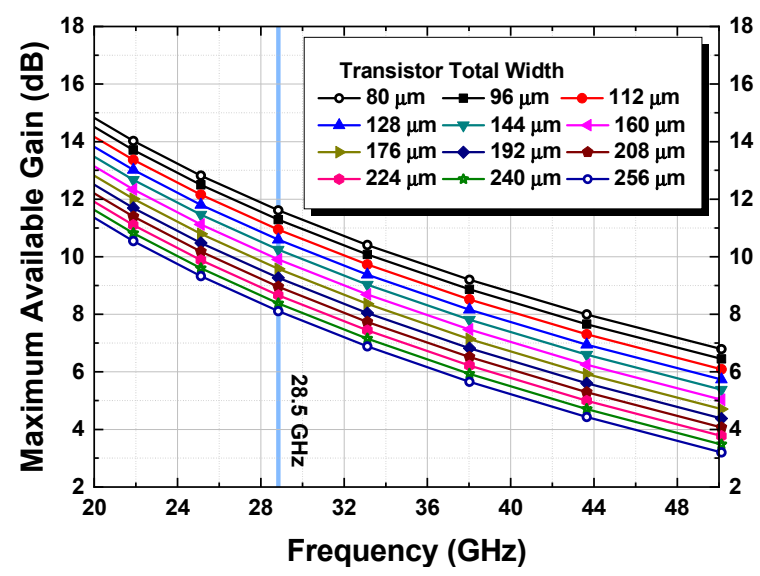

Figure 1. MAG of the unit amplifier based on the transistor gate width.

To determine the size of the transistor unit cell and the power stage, simulation of the output power, PAE, and load-pull of the unit amplifier was conducted; moreover, electromagnetic (EM) simulations of the transistor connections in the multiplier were also conducted. As seen in Figure 2, the output power increases with an increase in transistor size. However, PAE decreases, indicating inefficiency in further increasing the transistor size to achieve increased output power. Therefore, it is important to determine the (i) size of the transistor unit cell of the power stage, (ii) target output power, and (iii) the PAE to determine the appropriate transistor size. Particularly, to determine the size of the transistor, we must first determine the finger width, number of fingers, and multiplier size; however, the performance differs in each case due to parasitics, as shown in Figure 2. For example, the smaller the finger width, the smaller is the parasitic gate resistance inside the transistor; therefore, the $4 \mu \mathrm{m}$ finger width (red line) has a much lower PAE. For $1 \mu \mathrm{m}$ finger width (black line), many multipliers must be used to achieve high power, which results in lower PAE owing to the parasitic component in the power cell layout. Thus, we used unit cell transistors in the power stage with a $2 \mu \mathrm{m}$ finger width in this study. Additionally, 32 fingers and 4 multipliers (total gate width: $256 \mu \mathrm{m}$ ) were used to achieve the target output power of $15 \mathrm{dBm}$ with margin. In this study, we designed a three-stage PA with transistor gate widths of 144, 192, and $256 \mu \mathrm{m}$ for each stage with a MAG of 10.5, 9.5 , and $8 \mathrm{~dB}$, respectively, and an expected total gain of $28 \mathrm{~dB}$. 


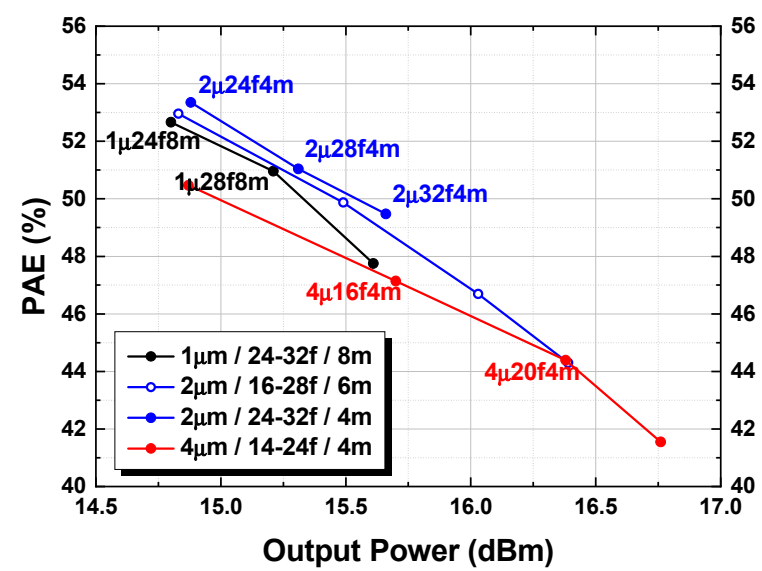

Figure 2. Load-pull simulation result of the unit amplifier based on the transistor size.

\subsection{Size Determination and Analysis of the Neutralized Capacitor}

Figure 3 shows the small-signal analysis model of the transistor. The admittance of each port is calculated using Equation (1). Each capacitance can be calculated individually, as shown in Equation (2).

$$
\begin{gathered}
y_{11}=s C_{g s}+s C_{g d}, \quad y_{12}=-s C_{g d} \\
y_{21}=g_{m}-s C_{g d}, \quad y_{22}=g_{d s}+s C_{d s}+s C_{g d} \\
C_{g d}=-\frac{i m\left(y_{12}\right)}{\omega}, \quad C_{g s}=\frac{i m\left(y_{11}+y_{12}\right)}{\omega}, \quad C_{g d}=\frac{i m\left(y_{22}+y_{12}\right)}{\omega}
\end{gathered}
$$
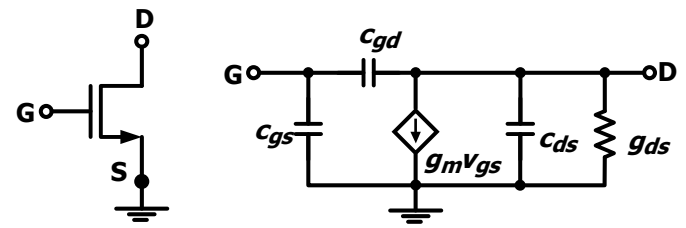

Figure 3. Small signal analysis model of the common source transistor.

For the transistor with $256 \mu \mathrm{m}$ gate width $(2 \mu \mathrm{m}$ unit finger width $\times 32$ fingers $\times$ 4 multipliers), the parasitic capacitances are estimated as $C_{g d}=72 \mathrm{fF}, C_{g s}=145 \mathrm{fF}$, and $C_{d s}=149 \mathrm{fF}$. Among the three parasitic capacitances, $C_{g d}$ in particular forms a feedback loop, resulting in instability in the PA. Therefore, to cancel out the $C_{g d}$, a capacitive neutralization method is generally used in the mm-wave PA. In general, the required neutralized capacitance $C_{n e u}$ is extracted by simulation tuning, however, in this study, quantitative $C_{n e u}$ was calculated based on $C_{g d}$ value. We first utilized a differential structure including $C_{n e u}$ to offset the feedback loop, after which the value of $C_{n e u}$ was extracted and the small-signal analysis was conducted.

Figure 4 a shows the circuit with $C_{n e u}$ applied to the differential common source structure. Figure $4 \mathrm{~b}$ shows the schematic representation of the small-signal model of the circuit shown in Figure $4 \mathrm{~b}$. The admittance of each port in the small-signal analysis model is calculated as:

$$
\begin{aligned}
i_{\text {in }} & =s C_{g s} v_{\text {in }}++s C_{g d}\left(\frac{v_{\text {in }}^{+}}{2}-\frac{v_{\text {out }}^{-}}{2}\right)+s C_{\text {neu }}\left(\frac{v_{\text {in }}^{+}}{2}-\frac{v_{\text {out }}^{+}}{2}\right) \\
& =s\left(C_{g s}+C_{g d}+C_{\text {neu }}\right) \frac{v_{\text {in }}^{+}}{2}-s\left(C_{g d}-C_{\text {neu }}\right) \frac{v_{\text {out }}^{-}}{2}
\end{aligned}
$$




$$
\begin{gathered}
i_{\text {out }}=\left(g_{d s}+s C_{d s}\right) v_{\text {out }}^{-}+g_{m} \frac{v_{\text {in }}^{+}}{2} \\
+s C_{g d}\left(\frac{v_{\text {out }}^{-}}{2}-\frac{v_{\text {in }}^{+}}{2}\right)+s C_{\text {neu }}\left(\frac{v_{\text {out }}^{-}}{2}-\frac{v_{\text {in }}^{-}}{2}\right) \\
=\left(g_{m}-s C_{g d}+s C_{\text {neu }}\right) \frac{v_{\text {in }}^{+}}{2}+\left(g_{d s}+s C_{g d}+s C_{g d}+s C_{\text {neu }}\right) \frac{v_{\text {out }}^{-}}{2} \\
Y=\left[\begin{array}{ll}
y_{11}=\left.\frac{i_{\text {in }}}{v_{\text {in }}}\right|_{v_{\text {out }}=0} & y_{12}=\left.\frac{i_{\text {in }}}{-v_{\text {out }}}\right|_{v_{\text {in }}=0} \\
y_{21}=\left.\frac{i_{\text {out }}}{v_{\text {in }}}\right|_{v_{\text {out }}=0} & y_{22}=\left.\frac{i_{\text {out }}}{-v_{\text {out }}}\right|_{v_{\text {in }}=0}
\end{array}\right] .
\end{gathered}
$$

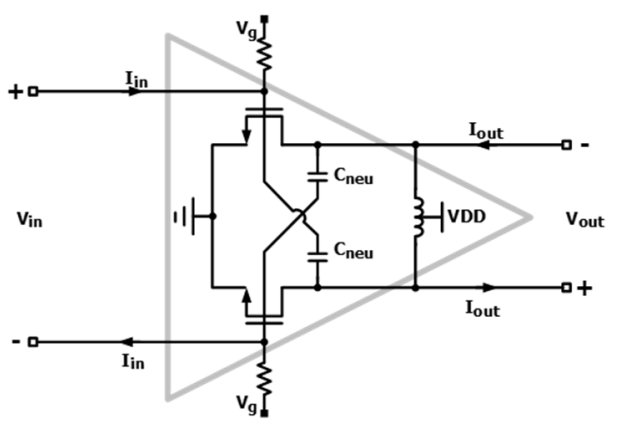

(a)

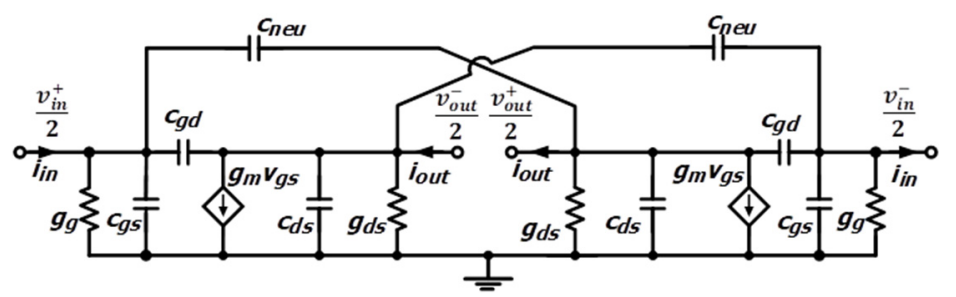

(b)

Figure 4. Schematic representation of (a) differential common source power cell, (b) small signal analysis model of (a).

When Equations (3) and (4) are substituted in Equation (5) for the arrangement, the admittance of the alternative power cell is obtained and is given as:

$$
\begin{array}{ll}
y_{11}=\frac{s C_{g s}+s\left(C_{g d}+C_{n e u}\right)}{2}, & y_{12}=-\frac{s\left(C_{g d}-C_{n e u}\right)}{2} \\
y_{21}=\frac{g_{m}-s\left(C_{g d}-C_{n e u}\right)}{2}, & y_{22}=\frac{g_{d s}+s C_{d s}+s\left(C_{g d}+C_{n e u}\right)}{2}
\end{array}
$$

As seen in Equation (6), the capacitance of the differential structure is halved, as compared to the single-end structure. Further, the maximum stable gain (MSG), MAG, and stability factor $(\mathrm{K})$ are calculated as [6]:

$$
\begin{gathered}
M S G=\frac{\left|y_{21}\right|}{\left|y_{12}\right|}=\frac{\left|g_{m}-s\left(C_{g d}-C_{\text {neu }}\right)\right|}{\left|-s\left(C_{g d}-C_{\text {neu }}\right)\right|}=\frac{\sqrt{g_{m}^{2}+\omega^{2}\left(C_{g d}-C_{n e u}\right)^{2}}}{\omega\left|C_{g d}-C_{\text {neu }}\right|} \\
M A G=M S G \cdot\left(K-\sqrt{K^{2}-1}\right) \\
K=\frac{2 \operatorname{Re}\left\{y_{11}\right\} \cdot \operatorname{Re}\left\{y_{22}\right\}-\operatorname{Re}\left\{y_{12} \cdot y_{21}\right\}}{\left|y_{12} \cdot y_{21}\right|} \\
=\frac{2 g_{g g} \cdot \partial_{d s}+\omega^{2}\left(C_{g d}-C_{\text {neu }}\right)^{2}}{\omega\left|C_{g d}-C_{\text {neu }}\right| \sqrt{\omega^{2}\left(C_{g d}-C_{\text {neu }}\right)^{2}+g_{m}^{2}}} \\
K>1, \quad \operatorname{Re}\left\{y_{11}\right\}>0, \quad \operatorname{Re}\left\{y_{22}\right\}>0
\end{gathered}
$$


To conveniently determine $\mathrm{K}$, a series parasitic resistance of the gate was equivalent to a parallel parasitic resistance, $g_{g}$, to satisfy the condition in Equation (10). The simulation results of K, MSG, and MAG, based on the values of $C_{\text {neu }}$ in a single-stage differential PA at $28 \mathrm{GHz}$, are shown in Figure 5. As $\left|C_{g d}-C_{n e u}\right|$ decreases, K and MSG increase with smaller denominators and achieve the highest value when $C_{g d}$ and $C_{n e u}$ are equal. Thus, adjusting the $C_{\text {neu }}$ can deliver additional gain and stability in the PA. Consequently, although the oscillation risk is particularly high in the high-gain three-stage PA, this can be solved by analyzing the parasitic capacitance of the transistors and the subsequent optimization of capacitive neutralization.

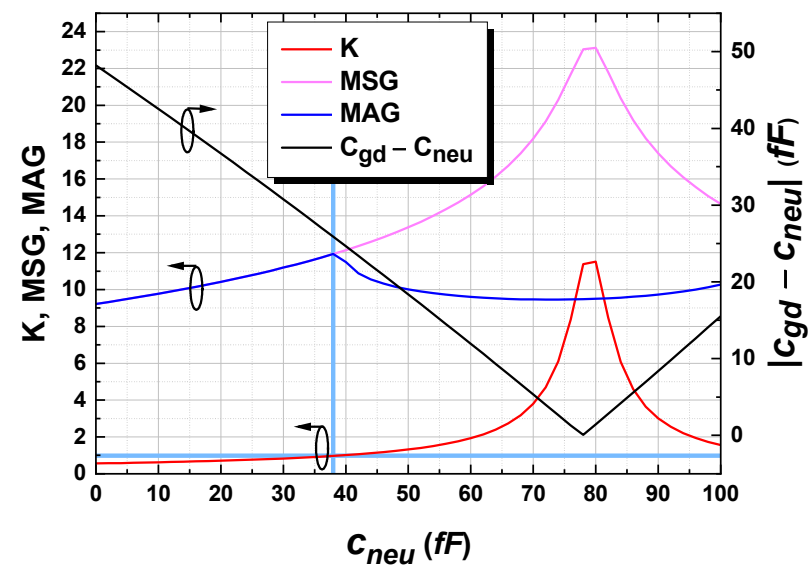

Figure 5. Simulated result of stability factor, MSG, and MAG.

\subsection{Analysis of Parasitices Caused by Power Cell Layout}

Given that the power cell comprises several unit transistors, the parasitic components induced by various interconnecting lines and contacts are included in the simulation analysis to ensure accurate results. In this section, the effects of parasitic components are identified by comparing the schematic simulation results and the EM simulation results, while considering the layout of the power cell. Additionally, we present the analysis process in the power stage of the PA to ensure convenience.

Figure 6 shows the power cell layout of the designed PA, comprising of wide and long metal lines for interconnections, which generate various parasitic resistances, inductances, and capacitances. EM simulation was performed to consider the parasitic components of the power cell through the layout shown in Figure 6. Considering the interconnect lines and contacts, $C_{g d}, C_{g s}$, and $C_{d s}$ increase by $10 \%$, to $7.7 \mathrm{fF}, 19.9 \mathrm{fF}$, and $19.2 \mathrm{fF}$, respectively, which is sufficient to affect the overall performance of the PA.

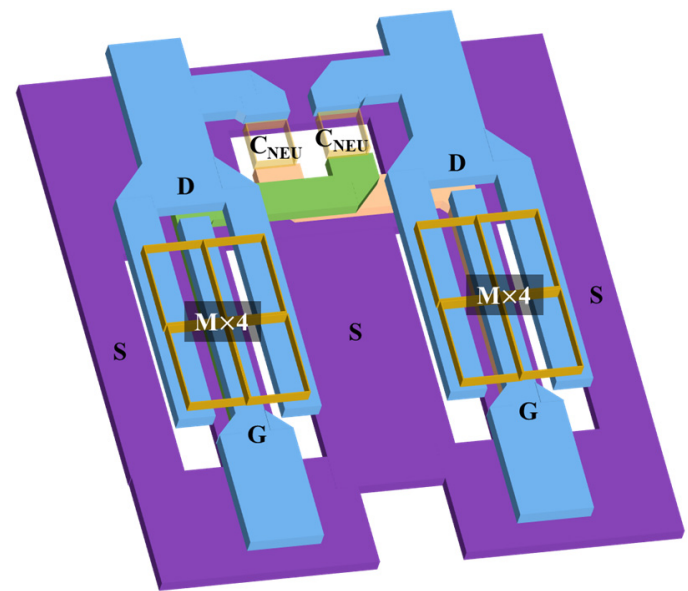

Figure 6. Power cell layout for the proposed design. 
The difference in the estimations with and without EM simulations based on the results from Figure 6 is shown in Figure 7. Figure 7a shows that the operating frequency was downshifted due to the additional parasitic capacitance extracted from the EM simulation of the power cell layout; moreover, considering the parasitic components induced by the first and second stages would cause severe performance degradation in the power cell. As shown in Figure 7b, from the results of the continuous wave simulation at each center frequency (with parasitic components: $28 \mathrm{GHz}$ and w/o parasitic components: $30 \mathrm{GHz}$ ), we can confirm that loss is mainly caused by the parasitic resistance. Consequently, the gain and saturation output power decreased by $2 \mathrm{~dB}$ and $0.5 \mathrm{~dB}$, respectively, and PAE decreased by $3 \%$. Additionally, considering these parasitic components affect the optimization values of $C_{n e u}$ and have a significant impact on stability or bandwidth, an accurate EM analysis is required. In this study, the target operating frequency is $28.5 \mathrm{GHz}$, so the PA is designed by considering the downshift induced by the parasitic components of the power cell.

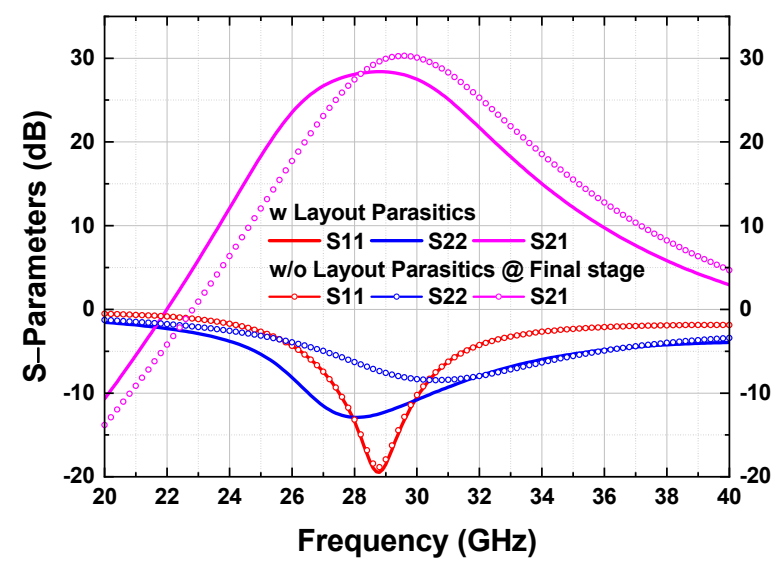

(a)

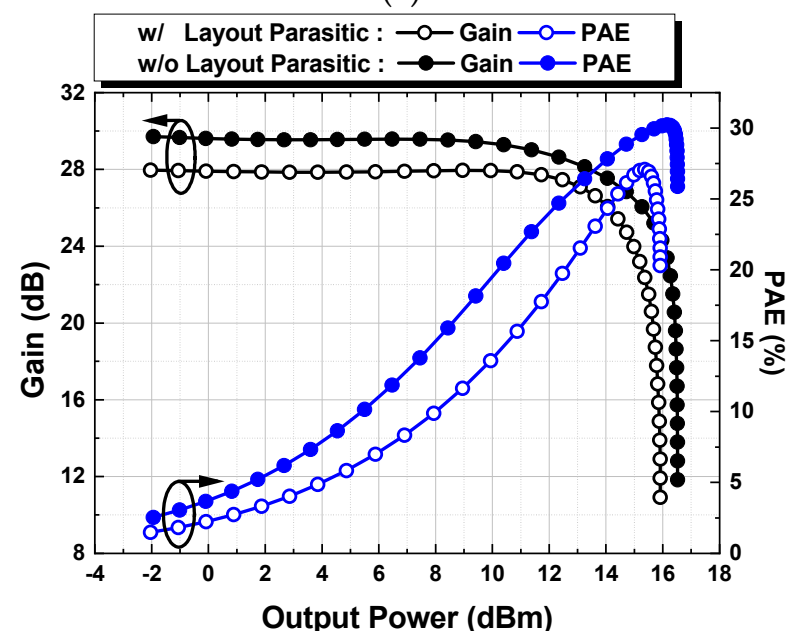

(b)

Figure 7. Simulation result of (a) s-parameters and (b) gain. PAE with or without power cell layout parasitic components in the power stage of three-stage PA.

\subsection{Configuration of Matching Network with Transformers}

Figure 8 shows a schematic of the designed PA, which comprises a three-stage configuration, each stage consisting of a common source structure. The matching process at each stage is shown in Figure 9. The smith charts shown in Figure 9 were normalized to $50 \Omega$. Figure 9a shows the input and interstages matched with the conjugate to minimize loss during signal transmission. In the input matching network, $Z_{S}$ and input impedance of the first stage should match the conjugate. $Z_{S, M}$ should match $Z_{S, 1 s t, \text { Conj }}$ as much as possible, through which, $Z_{\text {in, Matched }}$ is converted to $63.95 \Omega$ close to $50 \Omega$. The 
input matching network was constructed considering the bandwidth rather than exact matching values. Figure $9 b, c$ shows that the output impedances of the first and second stages are conjugate matched with the input impedance of the next stages through the inter-stage matching network. Finally, Figure $9 \mathrm{~d}$ shows the process of matching $Z_{L}$ by obtaining the optimized output impedance $Z_{O p t}$ for maximum output power and PAE. Through load-pull simulation, $Z_{\text {Opt,Pout }}$ and $Z_{\text {Opt,PAE }}$ were found to be $13+j 8.9 \Omega$ and $12.6+j 15.4 \Omega$, respectively. $Z_{\mathrm{L}}$ is converted to $11+\mathrm{j} 13.4 \Omega$ through an output matching network (OMN) consisting of transformers and an output parallel capacitor (OPC). When the output impedance corresponds to $Z_{\mathrm{Opt}, P o u t}$ and $Z_{\mathrm{Opt}, P A E}$, the maximum output power and PAE are $15.4 \mathrm{dBm}$ and $27.2 \%$, respectively, and the expected values with $50 \Omega$ load impedance are $15.3 \mathrm{dBm}$ and $26.4 \%$, respectively. The EM simulation was performed throughout the PA, including matching networks, transformers, pads, and connection lines between devices.

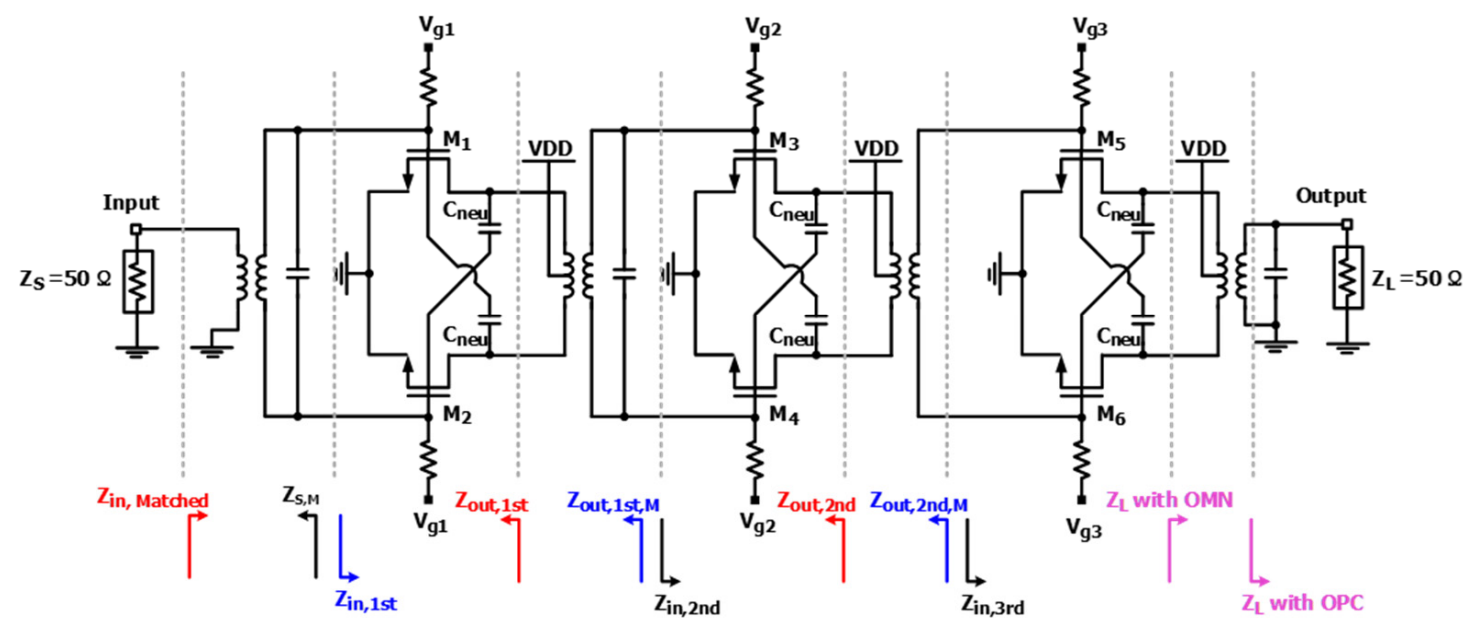

Figure 8. Schematic of the proposed three-stage PA.

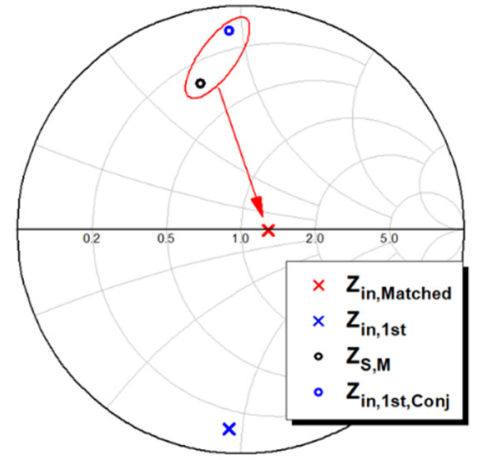

(a)

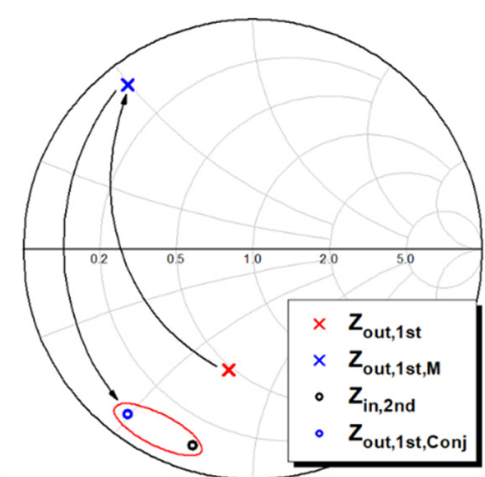

(b)

Figure 9. Cont. 


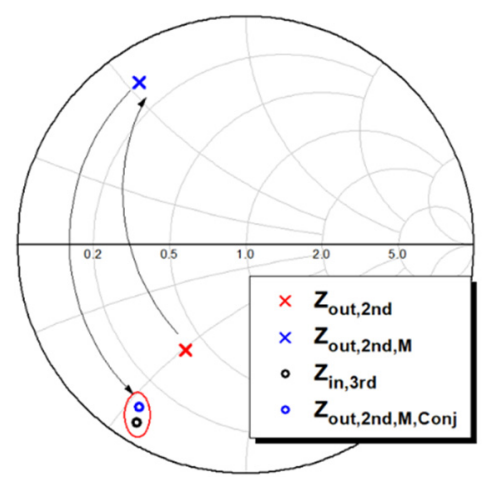

(c)

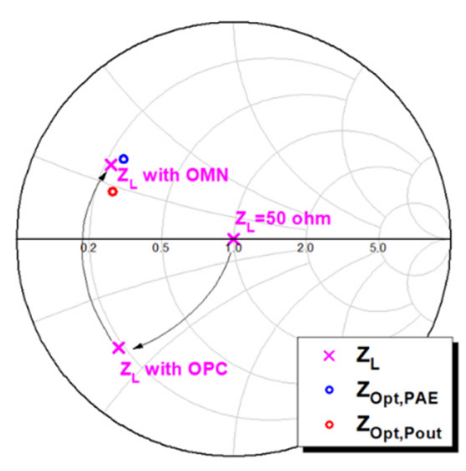

(d)

Figure 9. Simulation results of matching networks: (a) input conjugate matching, (b) conjugate matching for first and second stages, (c) conjugate matching for second and power stages, and (d) output matching for $Z_{L}$ with $Z_{\text {opt }}$ through load-pull simulation.

\section{Measured Results}

We designed a three-stage differential PA using a $65 \mathrm{~nm}$ RFCMOS, as seen in Figure 10 which shows a photograph of the designed PA. The total size of the PA, including the pads, was $0.90 \times 0.50 \mathrm{~mm}^{2}$. and the core size of PA, excluding the pads and decoupling capacitors, was $0.74 \times 0.16 \mathrm{~mm}^{2}$. The s-parameter and power of the designed PA was measured using Rohde-Schwarz ZNA43 vector network analyzer.

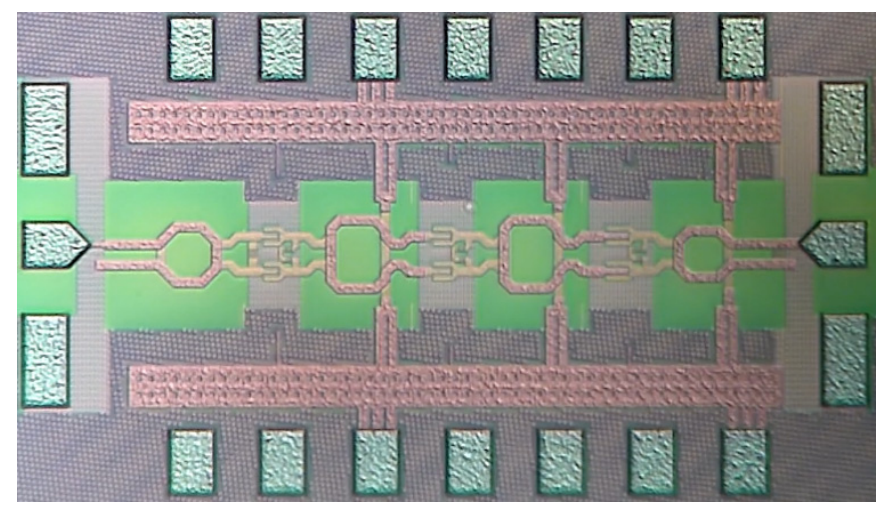

Figure 10. Chip photograph of designed three-stage PA.

Figure 11 shows the S-parameter measurement results for the designed PA, which was measured in all three stages with a $\mathrm{V}_{\mathrm{DD}}$ of $1 \mathrm{~V}$ and gate bias voltages of $330 / 350 / 350 \mathrm{mV}$. The measured standby current of the PA was $47 \mathrm{~mA}$, and the resulting current density of the transistor used was $40 \mu \mathrm{A} / \mu \mathrm{m}$. From $S_{21}$, the gain at $3 \mathrm{~dB}$ bandwidth is $4 \mathrm{GHz}(26.5-30.4 \mathrm{GHz})$. The measured $\mathrm{S}_{11}$ and $\mathrm{S}_{22}$ were below $-10 \mathrm{~dB}$, ranging between 26.5-29.2 GHz and 26.8-32.2 GHz, respectively; the difference between the measurement and simulation results were due to variation in the process, and the two results were similar because of rigorous EM simulations. The measurement results of the CW signal under the specified bias conditions are shown in Figure 12. The PA has a saturated output power of $16.1 \mathrm{dBm}$ at $28.5 \mathrm{GHz}$ and $13.1 \mathrm{dBm}$ at $\mathrm{P} 1 \mathrm{~dB}$ with a gain of $31.5 \mathrm{~dB}$. The maximum PAE was $29.7 \%$, whereas the PAE at P1dB was $22 \%$. The measurement results of the CW signal are similar to that in the preceding chapter; however, it differs in current and gain due to variation in the process, resulting in a higher gain and PAE than that in the simulation. Figure 13 shows the measurement results of $\mathrm{CW}$ signals with frequencies ranging between 26.5-29.5 GHz. The maximum PAE of $30.1 \%$ was achieved at $29 \mathrm{GHz}$, over $27 \%$ in the higher bandwidths, and between $20.5-23 \%$ at $\mathrm{P} 1 \mathrm{~dB}$. The output power $\mathrm{P} 1 \mathrm{~dB}$ ranged between $12.8-13.7 \mathrm{dBm}$, and the saturated output power ranges between $15.4-16.4 \mathrm{dBm}$. 


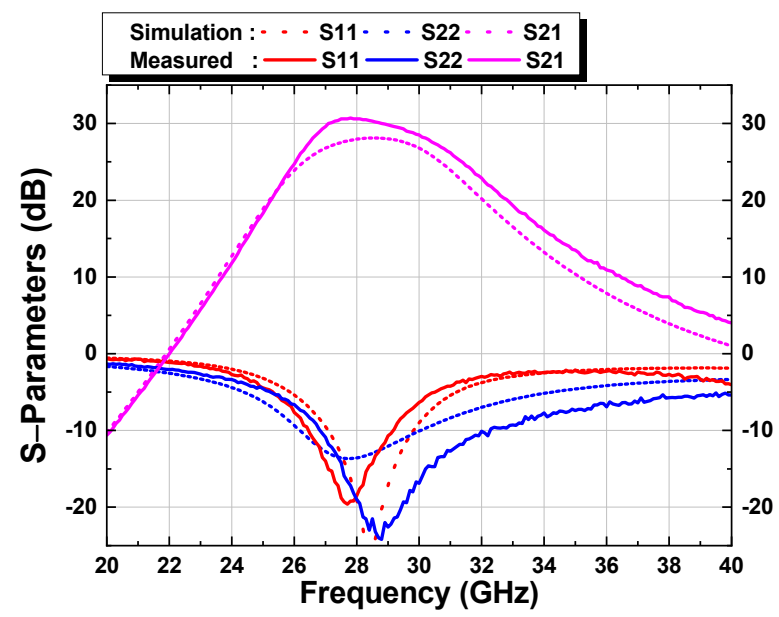

Figure 11. Measured s-parameters (solid) and simulated s-parameters (dot).

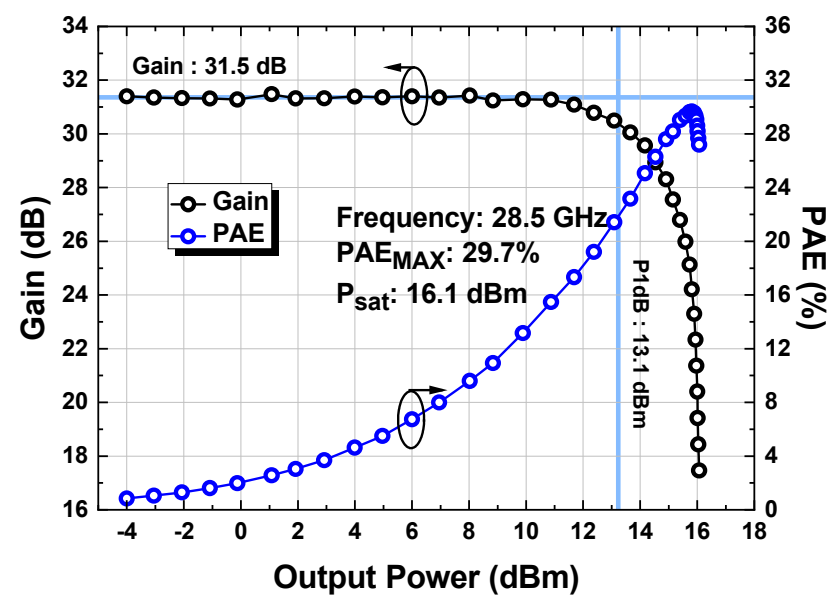

Figure 12. Measured gain and PAE versus output power with CW signal.

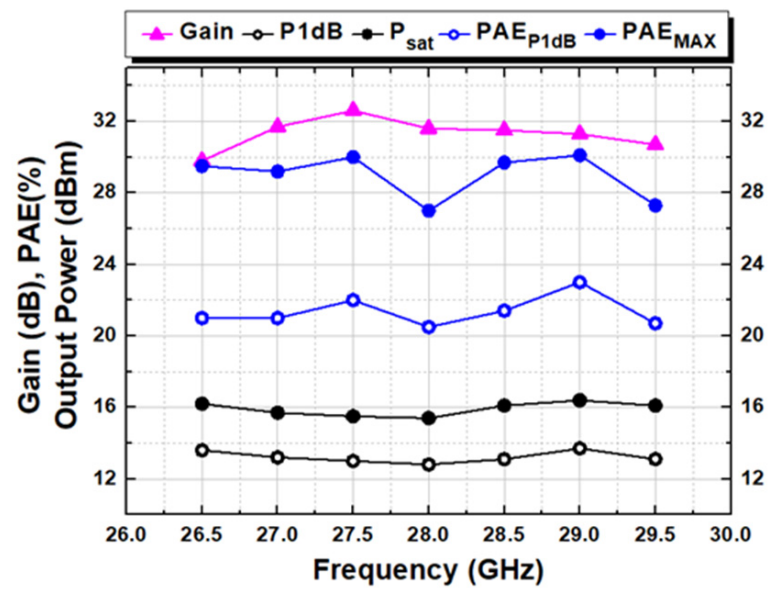

Figure 13. Results of CW signal measurements by frequency.

Table 1 shows a comparison of the performance of a designed PA with that of other CMOS PAs. The designed PA had a relatively high gain of $31.5 \mathrm{db}$ with a $P_{\text {sat }}$ of $16.1 \mathrm{dBm}$. 
Table 1. Performance comparison with state-of the art CMOS PAs.

\begin{tabular}{ccccccccc}
\hline Ref. & Tech. & $\begin{array}{c}\text { Freq. } \\
(\mathbf{G H z})\end{array}$ & $\begin{array}{c}\text { Supply } \\
\mathbf{( V )}\end{array}$ & $\begin{array}{c}\mathbf{P}_{\text {sat }} \\
\mathbf{( d B m})\end{array}$ & $\begin{array}{c}\text { P1dB } \\
\mathbf{( d B m})\end{array}$ & $\begin{array}{c}\text { Gain } \\
\mathbf{( d B})\end{array}$ & $\begin{array}{c}\text { Peak PAE } \\
\mathbf{( \% )}\end{array}$ & $\begin{array}{c}\text { Architecture } \\
\text { Three-stage } \\
\text { CS }\end{array}$ \\
\hline This work & $65 \mathrm{~nm}$ & 28.5 & 1.0 & 16.1 & 13.1 & 31.5 & $\begin{array}{c}\text { Two-stage } \\
\text { Cascode }\end{array}$ \\
\hline $\begin{array}{c}\text { TMTT' } 21 \\
{[2]}\end{array}$ & $65 \mathrm{~nm}$ & 31 & 2.2 & 17.1 & 15 & 18.9 & 38.2 & $\begin{array}{c}\text { Two-stage } \\
\text { Cascode }\end{array}$ \\
\hline $\begin{array}{c}\text { TCASII' } 21 \\
{[9]}\end{array}$ & $28 \mathrm{~nm}$ & 26 & 2.2 & 20.3 & 18.2 & 21.2 & 33.1 & 26 \\
\hline $\begin{array}{c}\text { SSCL'20 } \\
{[10]}\end{array}$ & $28 \mathrm{~nm}$ & 28 & 1.8 & 21.5 & 20.7 & 20.4 & $\begin{array}{c}\text { Two-Stacked } \\
\text { Four way }\end{array}$ \\
\hline
\end{tabular}

\section{Conclusions}

We designed a PA operating between the $26.5-29.5 \mathrm{GHz}$ band using a $65 \mathrm{~nm}$ RFCMOS. The designed PA achieved a high gain of $30.7 \mathrm{~dB}$ at $27.8 \mathrm{GHz}$ by optimizing the size of the power cell and neutral capacitor $C_{n e u}$. Particularly, if a three-stage PA is configured, there is a rash risk due to high gain, and stability can be ensured only through strict EM simulations and analysis of parasitic components. The designed PA had a saturated power of $16.1 \mathrm{dBm}-13.1 \mathrm{dBm}$ at output P1dB, and a maximum PAE of $29.7 \%$.

Author Contributions: Conceptualization, H.J., H.L. and C.P.; methodology, B.P. and S.J.; Investigation, B.P. and S.K.; supervision, writing—original draft, H.J. and C.P.; writing—review and editing, H.J., H.L., B.P., S.J., S.K. and C.P. All authors have read and agreed to the published version of the manuscript.

Funding: This research was funded by Institute of Information \& Communications Technology Planning \& Evaluation (IITP) grant funded by the Korea government (MSIT) (2019-0-00933, Development on multi-beam antenna technology).

Institutional Review Board Statement: Not applicable.

Informed Consent Statement: Not applicable.

Data Availability Statement: The data can be received from the authors on request.

Conflicts of Interest: The authors declare no conflict of interest.

\section{References}

1. Zong, Z.; Tang, X.; Khalaf, K.; Yan, D.; Mangraviti, G.; Nguyen, J.; Liu, Y.; Wambacq, P. A 28-GHz SOI-CMOS Doherty power amplifier with a compact transformer-based output combiner. IEEE Trans. Microw. Theory Tech. 2021, 69, 2795-2808. [CrossRef]

2. Park, J.; Kang, S.; Hong, S. Design of a Ka-band cascode power amplifier linearized with cold-FET interstage matching network. IEEE Trans. Microw. Theory Tech. 2021, 69, 1429-1438. [CrossRef]

3. Cho, G.; Jeong, G.; Hong, S. 28-GHz CMOS power amplifier linearized with resistive drain-body connection. IEEE Microw. Wirel. Compon. Lett. 2020, 30, 876-879. [CrossRef]

4. Ding, B.; Yuan, S.; Zhao, C.; Tao, L.; Tian, T. A Ka band FMCW transceiver front-end with 2-GHz bandwidth in 65-nm CMOS. IEEE Trans. Circuits Syst. II Express Briefs 2019, 66, 212-216. [CrossRef]

5. Jia, H.; Prawoto, C.C.; Chi, B.; Wang, Z.; Yue, C.P. A full Ka-band power amplifier with 32.9\% PAE and 15.3-dBm power in 65-nm CMOS. IEEE Trans. Circuits Syst. I Regul. Pap. 2018, 65, 2657-2668. [CrossRef]

6. Deferm, N.; Reynaert, P. CMOS at millimeter wave frequencies. In CMOS Front Ends for Millimeter Wave Wireless Communication Systems; Springer: Berlin/Heidelberg, Germany, 2015; pp. 13-25.

7. Chen, Y.-C.; Lin, Y.-H.; Lin, J.-L.; Wang, H. A Ka-band transformer-based Doherty power amplifier for multi-Gb/s application in 90-nm CMOS. IEEE Microw. Wirel. Compon. Lett. 2018, 28, 1134-1136. [CrossRef]

8. Indirayanti, P.; Reynaert, P. A 32-GHz 20-dBm PSAT transformer-based Doherty power amplifier for multi-Gb/s 5G applications in 28-nm bulk CMOS. In Proceedings of the 2017 IEEE Radio Frequency Integrated Circuits Symposium, Honolulu, HI, USA, 4-6 June 2017; pp. 45-48.

9. Lee, J.; Hong, S. A $24-30 \mathrm{GHz} 31.7 \%$ fractional bandwidth power amplifier with an adaptive capacitance linearizer. IEEE Trans. Circuits Syst. II Express Briefs 2021, 68, 1163-1167. [CrossRef]

10. Manente, D.; Padovan, F.; Seebacher, D.; Bassi, M.; Bevilacqua, A. A 28-GHz stacked power amplifier with 20.7-dBm output P1dB in 28-nm bulk CMOS. IEEE Solid-State Circuits Lett. 2020, 3, 170-173. [CrossRef] 